\title{
PKM Jemaat GBI Kolongan Tentang Bencana-Bencana Geologis dan Mitigasinya
}

\author{
Guntur Pasau ${ }^{1^{*}}$, Ferdy $^{2}$ \\ 1,2 Jurusan Fisika, Fakultas Matematika Dan Ilmu Pengetahuan Alam \\ Universitas Sam Ratulangi \\ *Penulis Korespondensi. Email: guntur_pasau@unsrat.ac.id
}

\begin{abstract}
ABSTRAK
Secara geologis, wilayah Sulawesi Utara merupakan wilayah yang rawan bencana geologis karena merupakan tempat pertemuan beberapa lempeng tektonik aktif, seperti lempeng Filipina, lempeng Pasifik dan lempeng Eurasia. Ketiga lempeng tersebut saling bertumbukan satu dengan yang lain sehingga menyebabkan kerak bumi menjadi terpecah-belah dan dapat menimbulkan bencana geologis, baik gempa bumi maupun tsunami. Kedua bencana geologi ini merupakan fenomena alam yang masih sulit diprediksi. Bencana geologi seperti gempa bumi dan tsunami merupakan bencana alam yang selalu datang secara tiba-tiba. Salah satu antisipasi untuk meminimalisir dampak bencana geologi adalah dengan mempersiapkan diri melalui pemahaman tentang karakteristik bencana itu sendiri dan peningkatan kemampuan dalam menghadapi bencana tersebut. Kegiatan program kemitraan masyarakat ini bertujuan untuk memberikan pengetahuan, pemahaman dan ketrampilan kepada masyarakat sasaran tentang mitigasi bencana-bencana geologis. Sasaran kegiatan ini adalah anggota Jemaat GBI Shalom Kalawat Minahasa sebagai mitra dalam kegiatan ini. Metode pelaksanaan kegiatan Program Kemitraan Masyarakat terbagi dalam beberapa kegiatan yaitu sosialisasi, diskusi, tanya jawab dan simulasi bencana. Pemahaman materi berupa penyampaian materi tentang karakteristik bencana gempa dan tsunami serta tindakan mitigasinya. Kemudian simulasinya adalah bagaimana menyelamatkan diri dan orang lain ketika bencana tersebut terjadi. Hasil evaluasi yang dilakukan berupa pretest dan posttest dalam pemberian materi sosialisasi menunjukkan adanya peningkatan pemahaman pengetahuan dan ketrampilan dalam meminimalisir bahaya bencana gempa dan tsunami.
\end{abstract}

Kata kunci: Bencana Geologis, Mitigasi, Pengetahuan, Keterampilan, Simulasi

\begin{abstract}
Geologically, North Sulawesi is a region prone to geological disasters because it is a meeting place for several active tectonic plates, such as the Philippine plate, the Pacific plate and the Eurasian plate. The three plates collide with one another, causing the earth's crust to become fragmented and can cause geological disasters, both earthquakes and tsunamis. These two geological disasters are natural phenomena that are still difficult to predict. Geological disasters such as earthquakes and tsunamis are natural disasters that always come suddenly. One of the anticipations to minimize the impact of geological disasters is to prepare oneself through understanding the characteristics of the disaster itself and increasing skills in dealing with these disasters. This community service program activity aims to provide knowledge, understanding and skills to target communities about mitigating geological disasters. The target of this activity is members of the GBI Shalom Kalawat, North Minahasa congregation as partners in this activity. The method of implementing community service program activities is divided into several activities, namely socialization, discussion, question and answer and disaster simulation. Understanding the material in the form of delivering material about the characteristics of the earthquake and tsunami disasters and their mitigation measures. Then the simulation is how to save yourself and others when the disaster occurs. The results of the evaluation carried out in the form of a pre test and post test in providing socialization materials showed an increase in understanding of knowledge and skills in minimizing the danger of earthquake and tsunami disasters.
\end{abstract}

Keywords: Geological disaster, Mitigation, Knowledge, Skills, Simulation 
Jurnal Pengabdian Multidisiplin

\section{PENDAHULUAN}

\section{Analisis Situasi}

Secara geologis Sulawesi Utara merupakan wilayah yang rawan bencana-bencana geologis karena wilayah ini berada pada peretemuan beberapa lempeng tektonik aktif seperti lempeng Philipina, lempeng Pasifik, dan lempeng Eurasia (Pasau \& Tanauma, 2015) ditambah dengan beberapa patahan aktif di wilayah daratan seperti patahan Gorontalo (Santoso, 2010) dan beberapa patahan aktif lainnya. Lempeng-lempeng tersebut saling bertumbukan satu dengan lainnya meneyebabkan kulit bumi porak-poranda dan dapat menyebabkan bencana-bencana geologis baik gempa bumi maupun tsunami. Kedua bencana geologis ini merupakan gejala alam yang sampai sekarang masih sulit untuk diperkirakan kejadianannya, sehingga dapat dilihat bahwa gejala alam ini sifatnya seolah-olah datang mendadak dan tidak teratur.

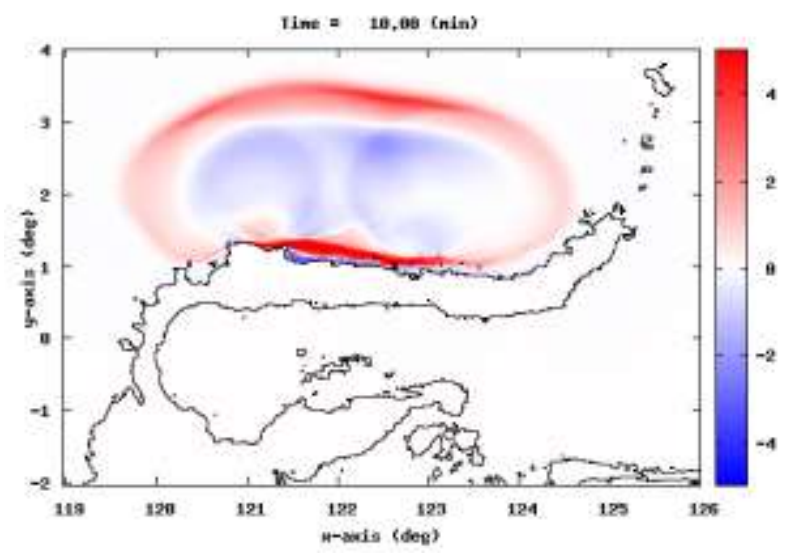

Gambar 1. Simulasi Penjalaran Tsunami di Pantai Utara Sulawesi Utara (Pasau, dkk 2019)

Beberapa gempa bumi merusak pernah terjadi disepanjang jalur gempa bumi di Sulawesi Utara seperti gempa Gorontalo (1990, 1991 dan 2009), gempa Manado (1980, 1988), gempa Toli Toli $(1983,1986)$ dan gempa-gempa laut Maluku yang hampir setiap tahun terjadi (Santoso, 2010). Sementara kejadian tsunami juga sudah beberapa kali melanda wilayah Sulawesi Utara baik yang terjadi di laut Sulawesi maupun akibat gempabumi di laut Maluku. Hasil Pemodelan tsunami (Gambar 1) menunjukkan bahwa tinggi tsunami yang dapat terjadi di pantai utara Sulawesi yakni sekitar 3-5 m dengan waktu tiba gelombang tsunami berkisar 15-20 menit setelah terjadinya gempa bumi (Pasau, 2019).
Berdasarkan kondisi tersebut di atas sehingga seyogyanya bahwa pemahaman kebencanaan utamanya bencana-bencana geologis disosialisasikan kepada masyarakat umum sehingga mereka memiliki pemahaman dan ketrampilan dalam menghadapi bencana apabila bencana sewaktuwaktu dapat terjadi. Penanggulangan bencana seharusnya tidak bersifat reaktif: baru melakukan setelah terjadi bencana. Tetapi penanggulangan bencana juga bisa bersifat antisipatif, melakukan pengkajian dan tindakan pencegahan untuk meminimalisir kemungkinan terjadinya bencana (Ahdi, 2015).

Upaya pengurangan risiko-resiko bencana baik yang sudah ada maupun usaha mencegah terjadinya risiko baru dapat dilakukan dengan meningkatkan ketangguhan masyarakat dalam menghadapi bencana. Masyarakat sebagai korban terdampak bencana memiliki risiko yang dapat berupa kematian, luka, sakit, jiwa terancam, dan hilangnya rasa aman, mengungsi, kerusakan atau kehilangan harta, dan gangguan kegiatan masyarakat risiko tersebut dapat dikurangi ataupun dicegah apabila ketangguhan telah terbentuk dalam diri masyarakat (Siregar, 2019)

Salah satu kelompok masyarakat yang berdomisili di Sulawesi Utara adalah kelompok masyarakat atau jemaat gereja GBI Shalom Kolongan Kecamatan Kalawat Minahasa Utara. Gereja GBI Jemaat Shalom Kolongan merupakan salah satu gereja beraliran Baptis tepatnya bernaung dibawah Gereja Baptist Independen di Sulawesi Utara. Gereja ini berawal dari persekutuan ibadah beberapa karyawan/ buruh PT. Holcim Indonesia Manado yang berada di Desa Kolongan Kec. Kalawat Kabupaten Minahasa Utara. Sebagian besar dari karyawan tersebut adalah para perantau dari luar Sulawesi Utara, ada yang dari Palu, Kupang, Makassar dan Pulau Jawa. Kemudian pada tahun 2014 mereka sudah mulai memebentuk sebuah persekutuan yang lebih besar dan mendirikan sebuah organisasi keagamaan atau badan yang mereka sebut sebagai GBI Shalom Jemaat Kolongan. Saat ini anggota jemaat gereja ini berjumlah kurang lebih 20 Kepala Keluarga dengan jumlah anggota jemaat sekitar 50-60 orang yang sebagaian besarnya masih berusia mudah dan anak-anak.

Anggota Jemaat GBI Shalom Kolongan sebagian besar berprofesi sebagai buruh pabrik semen, buruh pabrik kopra, tukang kayu/batu, sopir dan karyawan perusahaan swasta lainnya. Jika ditinjau dari tingkat pendidikan sebagian besar anggota jemaat ini mempunyai tingkat pendidikan 


\section{Jurnal Pengabdian Multidisiplin}

yang sangat rendah yakni tamatan SD dan SMP hanya sebagaian kecil saja yang tamat SMA.

\section{Tujuan dan Manfaat Kegiatan}

Tujuan dari kegiatan PKM (Program Kemitraan Masyarakat) ini adalah memberikan pengetahuan dan pemahaman kepada masyarakat sasaran tentang karakteristik bencana-bencana geologis dan mitigasinya. Sedangkan manfaat kegiatan ini adalah memberikan kemampuan ketrampilan minimum yang harus dimiliki seseorang untuk menyelamatkan diri dan orang lain dari bencanabencana geologis jika bencana tersebut terjadi kapan dan dimana saja. Sehingga dengan demikian maka masyarakat akan memiliki rasa aman dan menimbulkan kepercayaan diri untuk menghadapi ancaman bencana-bencana geologis.

\section{METODE PELAKSANAAN \\ Sasaran kegiatan}

Sasaran dalam kegiatan Program Kemitraan Masyarakat (PKM) ini adalah Anggota Jemaat gereja GBI Shalom Kolongan Kecamatan Desa Kalawat Kabupaten Minahasa Utara.

Metode pelaksanaan dari kegiatan Program Kemitraan Masyarakat (PKM) ini disesuaikan dengan permasalahan yang dihadapi oleh mitra sasaran yakni: pertama kurangnya pengetahuan dan kemampuan mitra sasaran tentang karakteristik bencana-bencana geologis dan kedua mitra tidak memiliki ketrampilan minimum dalam meyelamatkan diri dan orang lain saat terjadi bencana geologis.

\section{Lokasi kegiatan}

Rangkaian kegiatan secara umum dilaksanakan di Gedung Pertemuan Gereja GBI Shalom Kolongan Desa Kolongan, Kecamatan Kalawat, Kabupaten Minahasa Utara.

\section{Metode yang digunakan}

Materi yang diberikan selama pengabdian masyarakat berupa pengertian gempa bumi, tsunami, karakteristik gempa bumi dan tsunami, mitigasi bencana gempa bumi dan tsunami, dan simulasi bencana. Sebelum kegiatan penyuluhan dilaksanakan peserta mengerjakan soal pretest yang bertujuan untuk mengetahui pengetahuan awal peserta tentang bencana dan mitigasi bencana gempa bumi dan tsunami yang nantinya menjadi bahan evaluasi diakhir kegiatan untuk mengetahui keefektifan program kemitraan masyarakat yang dilakukan.
Pelaksanaan kegiatan pengabdian ini dilakukan melalui metode ceramah/penyuluhan, pelatihan simulasi bencana dan diskusi yang dilakukan di lokasi mitra. Adapun tahap-tahap pelaksanaan kegiatan pengabdian ini adalah sebagai berikut:

1. Tahap persiapan: Tahap persiapan meliputi koordinasi dengan mitra untuk kesediaan kerjasama dalam program pengabdian masyarakat, menyusun jadwal kegiatan dan melakukan pembagian tugas tim pelaksana. Materi penyuluhan dibuat menggunakan media power point presentation (ppt) yang akan ditampilkan melalui LCD proyektor, agar proses penyampaian (transfer) informasi kepada peserta bisa lebih cepat dan mudah diterima. Sebagian dari materi ini berupa animasi agar mudah dipahami oleh peserta.

2. Tahap pelaksanaan: Sebelum pemberian materi penyuluhan disampaikan dilaksanakan pretest terlebih dahulu untuk mengukur tingkat pengetahuan dan pemahaman peserta tentang karakteristik bencana dan mitigasinya. Jumlah peserta dalam kegiatan program kemitraan masyarakat ini sebanyak 25 orang. Soal dibuat dalam dua kelompok soal yakni bagian 1 berisi pemahaman dan karakeristik bencana-bencana geologis, sedangkan bagian kedua beirisi tentang tingkat kepercayaan diri saat menghadapi bencana-bencana geologis. Masing-masing bagian terdiri dari 10 nomor sehingga jumlah seluruhnya ada 20 soal. Soal-soal berisi materi yang akan disampaikan pada saat penyuluhan. Pada tahap kegiatan ini dilakukan dalam bentuk ceramah serta dialog interaktif dengan peserta. Materi disajikan dalam bentuk presentasi audiovisual agar lebih menarik dan lebih mudah dipahami oleh peserta. Penyampaian materi dilaksanakan selama 90 menit, yang terdiri dari pemaparan materi dan diskusi atau tanya jawab. Setelah penyuluhan selesai peserta mengerjakan soal post test yang berisi dan jumlah sama seperti dengan soal pretest sebelumnya. Hal ini dilakukan untuk mengetahui seberapa banyak informasi yang bisa diterima oleh peserta selama proses penyuluhan berlangsung.

\section{Praktek/Simulasi}

Tahap berikutnya adalah praktik langsung atau simulasi mitigasi bencana gempa bumi dan tsunami. Pada tahap simulasi bencana ini terbagi atas dua yakni:

a. Simulasi Gempa bumi 


\section{Jurnal Pengabdian Multidisiplin}

Simulasi gempa bumi berisi cara menyelamatkan diri agar terhindar dari jebakan maupun reruntuhan bangunan akibat gempa bumi maupun akibat-akibat lain yang mungkin dapat ditimbulkan oleh gempa bumi. Pada tahap ini peserta mempraktekkan cara bagaimana menghadapi gempabumi dan

\section{b. Simulasi tsunami}

Simulasi tsunami atau tsunami drill yang berisi tentang cara menyelamatkan diri dari bencana tsunami termasuk di dalamnya cara mengenali tanda-tanda alam akan terjadinya tsunami.

\section{HASIL DAN PEMBAHASAN}

Beberapa ciri dari masyarakat yang tanggap akan bencana antara lain adalah sudah terbentuknya pengetahuan dan ketrampilan menyelamatkan diri melalui latihan mitigasi (Tamuntuan, 2019). Oleh karena itu penyuluhan atau sosialiasi bertema Bencana-Bencana Geologis dan Mitigasinya di gereja GBI Shalom Kolongan Kecamatan Kalawat Kabupaten Minahasa telah dilaksanakan pada tanggal 26 September 2020 bertempat di Aula Pertemuan Gereja GBI Shalom Kolongan. Tim PKM berjumlah 6 orang yang terdiri atas 2 orang dosen dan 4 orang mahasiswa. Peserta yang hadir berjumlah 25 orang terdiri yang terdiri atas pendeta dan anggota jemaat.

Kegiatan diawali dengan doa bersama yang dibawakan oleh salah satu anggota jemaat dan dilanjutkan dengan sambutan masingmasing oleh Ketua Tim Pelaksana PKM yakni Guntur Pasau, S.Si, M.Si dan Pdt. Marthin Nomtanis, S.Th sebagai Pendeta Jemaat. Kemudian dilanjutkan dengan pemberian soal pretest ke peserta sebelum acara sosialisasi. Acara berikutnya adalah penyajian materi sosialisasi yaitu:

1. Pengenalan Gempa Bumi, Tsunami, Karakteristik dan Mitigasinya oleh Guntur Pasau, S.Si., M.Si.

2. Praktek/Simulasi oleh Ferdy, S.Si., M.Si

Secara umum, semua peserta yang berjumlah 25 orang mengikuti pelaksanaan kegiatan program kemitraan masyarakat secara sungguh-sungguh, baik dalam mendengarkan penyajian materi maupun dalam melakukan praktek atau simulasi bencana yang diberikan (Gambar 2). Beberapa pokok materi yang disampaikan dimulai dari struktur interior bumi, teori tektonik lempeng, konveksi di mantel, proses terjadinya gempa bumi dan tsunami, dampak bencana gempa bumi dan tsunami, cara penyelamatan diri saat terjadi gempa bumi dan tsunami, dan cara mengantisipasi kejadian gempa bumi dan tsunami. Penyampaian materi semua dilakukan secara audiovisual dengan metode diskusi kelas dan tanya jawab. Sedangkan materi simulasi bencana yang dilakukan selama pelatihan terdiri atas cara menyelamatkan diri sebelum, saat dan sesudah terjadi gempa bumi baik berada di dalam ruangan maupun di luar ruangan bahkan saat berada di dalam kendaraan. Pada sesi simulasi ini juga diajarkan cara memberikan pertolongan pertama kepada penderita korban Dalam praktik pemberian pertolongan kepada korban yang dilakukan dalam bentuk pemberian obat merah dan membalut luka serta cara mengevakuasi korban.

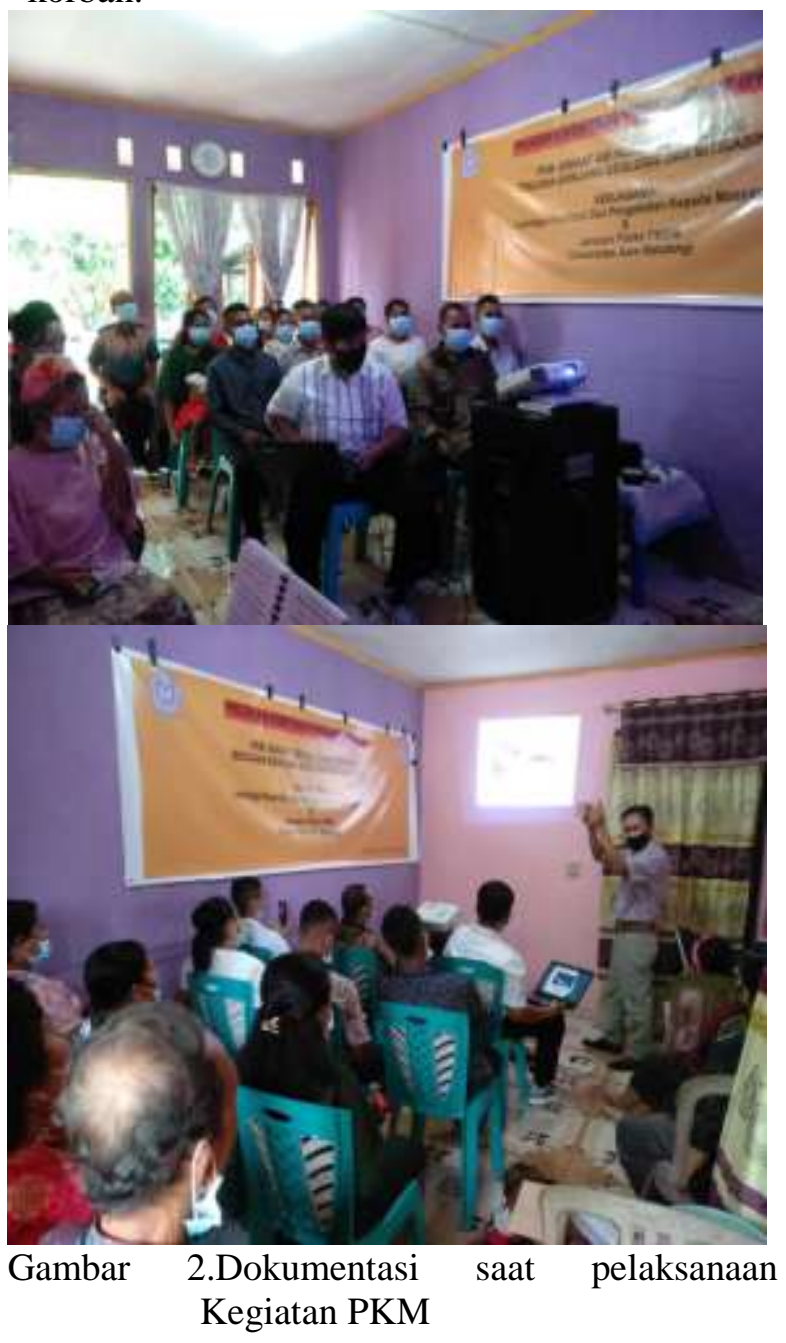

Evaluasi program kegiatan kemitraan masyarakat dilakukan melalui pretest maupun 


\section{Jurnal Pengabdian Multidisiplin}

postest. Berdasarkan distribusi data jawaban setiap peserta, maka dilakukan kategorisasi berdasarkan simpangan baku (SD) kedalam tiga klasifikasi yakni Tinggi (T), Sedang (S) dan Rendah (R) (Wirawan, 2016). Berdasarkan klasifikasi ini maka hasil dari evaluasi peserta seperti terlihat dalam Tabel 1 dan Tabel 2 berikut:

Tabel 1. Tingkat Pemahaman sebelum dan setelah penyuluhan/sosialisasi

\begin{tabular}{|l|c|c|c|c|}
\hline \multirow{2}{*}{ Pemahaman } & \multicolumn{2}{|c|}{ Pretest } & \multicolumn{2}{c|}{ Postest } \\
\cline { 2 - 5 } & $f$ & $\%$ & $f$ & $\%$ \\
\hline rendah & 16 & 64 & 1 & 4 \\
\hline sedang & 5 & 20 & 5 & 20 \\
\hline tinggi & 4 & 16 & 19 & 76 \\
\hline
\end{tabular}

dimana $f$ : frekuensi; \%: prosentase

Tabel 1 memperlihatkan data bahwa terjadi peningkatan tingkat pengetahuan dan pemahaman sebelum dengan setelah penyuluhan/ sosialisasi. Pada saat pretest masih ditemukan adanya tingkat pengetahuan yang rendah, namun setelah menjalani pelatihan tingkat pengetahuan bergeser ke tingkat pengetahuan sedang dan tinggi. Hal ini menunjukkan hal yang positif tentang manfaat dari pemberian materi lewat sosialisasi/ penyuluhan.

Tabel 2.Kepercayaan diri peserta sebelum dan setelah penyuluhan/sosialisasi

\begin{tabular}{|l|c|c|c|c|}
\hline \multirow{2}{*}{ Kepercayaan } & \multicolumn{2}{|c|}{ Pretest } & \multicolumn{2}{c|}{ Postest } \\
\cline { 2 - 5 } & $f$ & $\%$ & $f$ & $\%$ \\
\hline rendah & 18 & 72 & 3 & 12 \\
\hline sedang & 4 & 16 & 4 & 16 \\
\hline tinggi & 3 & 12 & 18 & 72 \\
\hline
\end{tabular}

dimana $f$ : frekuensi; \%: prosentase

Tabel.2 juga memperlihatkan bahwa sikap kepercayaan diri dan memiliki rasa aman dalam menghadapi bencana, sebelum dan sesudah penyuluhan/ sosialisasi dilakukan, mengalami peningkatan. Jika sebelum diberikan sosialisasi sebagian besar dari peserta masih kurang percaya diri dalam menghadapi bencana maka setelah diberikan pelatihan ini maka kepercayaan diri dari peserta sangat meningkat.

Analisis dari hasil prestest dan postest yang diberikan kepada peserta ditunjukkan pada grafik 1 dan grafik 2. Dari grafik 1 di dibawah menunjukkan bahwa sebagian besar peserta sebelum dilakukan kegiatan penyuluhan/sosialisasi tidak mempunyai pengetahuan dan pemahaman yang benar terhadap bencana-bencana geologis yakni berada kategori rendah sebanyak $64 \%$ dan tidak memiki kepercayaan diri juga berada pada kategori rendah sebesar $72 \%$.

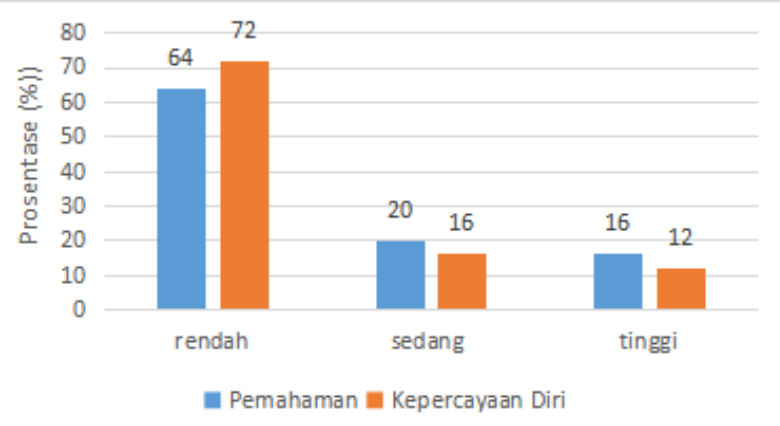

Grafik 1. Tingkat Pemahaman dan Kepercayaan Diri Peserta Sebelum Penyuluhan/ Sosialisasi

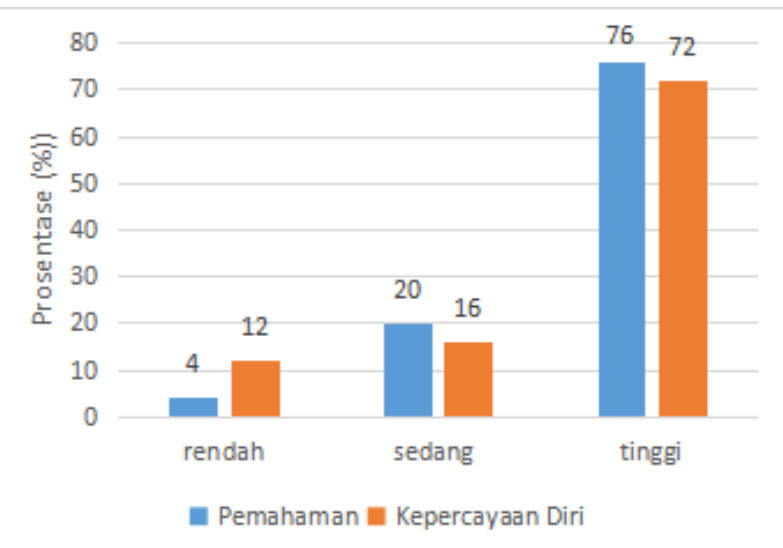

Grafik 2. Tingkat Pemahaman dan Kepercayaan Diri Peserta Sesudah Penyuluhan/ Sosialisasi

Dari grafik 2 di atas menunjukkan bahwa peserta secara umum setelah dilakukan penyuluhan memiliki pengetahuan dan pemahaman bencana yakni berada pada kategori tinggi yaitu sebesar 76\% dan untuk kepercayaan diri dalam menghadapi bencana geologis juga berada pada kategori tinggi yaitu sebesar $72 \%$.

\section{KESIMPULAN DAN SARAN}

Program Kemitraan Masyarakat (PKM) untuk memberikan pengetahuan dan ketrampilan mitigasi bencana-bencana geologis di Jemaat GBI Shalom Kolongan Kabupaten Minahasa Utara telah dilakukan dalam bentuk pemberian materi (sosialisasi/ penyuluhan) serta memberikan ketrampilan dalam menyelamatkan diri dan orang lain dari bencana-bencana geologis. Hasil evaluasi menunjukan terjadinya peningkatan pengetahuan dan kemampuan serta memiliki rasa percaya 
diri/rasa aman dalam menghadapi bencanabencana geologis.

\section{UCAPAN TERIMAKASIH}

Terima kasih diucapkan kepada Pendeta dan anggota Jemaat gereja GBI Shalom Kolongan Kecamatan Kalawat Kabupaten Minahasa Utara, atas dukungan dan kerjasamanya dalam kegiatan PKM. Ucapan terima kasih juga disampaikan kepada pihak LPPM Universitas Sam Ratulangi yang telah memberikan dukungan dana melalui skim Program Kemitraan Masyarakat (PKM) Tahun 2020.

\section{DAFTAR PUSTAKA}

Ahdi D. 2015. Perencanaan Penanggulangan Bencana Melalui Pendekatan Manajemen Resiko. REFORMASI 5 (1): 13-30

Pasau G., Tanauma A. 2015. Analisis Resiko Gempa Bumi Wilayah Lengan Utara Sulawesi Menggunakan Data Hiposenter Resolusi Tinggi Sebagai Upaya Mitigasi Bencana. Spektra: Jurnal Fisika dan Aplikasinya 16 (3): 6-10.

Pasau, G., Tamuntuan G H, Tanauma A. 2019. Numerical modelling for tsunami wave propagation (case study: Manado bays). IOP Conf. Ser.: Mater. Sci. Eng. 567012005

Santoso, Soehaimi A. 2010. Analisis Bahaya Gempa Lengan Utara Sulawesi. Jurnal Sumber Daya Geologi 20 (6): 317-323

Siregar J S, Wibowo A. 2019. Upaya Pengurangan Resiko Bencana pada Kelompok Rentan. Jurnal Dialog Penanggulangan Bencana 10 (1): 30-38.

Tamuntuan G H., Pasau G., Takumansang E. 2019. Peningkatan Kapasitas Masyarakat Untuk Kesiap-siagaan dan Mitigasi Bencana Tsunami di Desa Borgo Kabupaten Minahasa. VIVABIO 1(3): 17

Wirawan N. 2016. STATISTIKA: Ekonomi dan Bisnis. Penerbit Keraras Emas. Denpasar 